\title{
Estimation of Slip Distribution of the 2007 Bengkulu Earthquake from GPS Observation Using Least Squares Inversion Method
}

\author{
Moehammad Awaluddin $^{1,2}$, Irwan Meilano ${ }^{2} \&$ Sri Widiyantoro $^{3}$ \\ ${ }^{1}$ Geodetic Engineering, Faculty of Engineering, University of Diponegoro, \\ Jl. Prof. Soedharto Tembalang, Semarang 50255, Indonesia \\ ${ }^{2}$ Geodesy Research Division, Faculty of Earth Science and Technology, \\ Institut Teknologi Bandung, Jl. Ganesha, 10 Bandung 40132, Indonesia \\ ${ }^{3}$ Global Geophysics Research Division, Faculty of Mining and Petroleum Engineering, \\ Institut Teknologi Bandung, Jl. Ganesha 10, Bandung 40132, Indonesia \\ Email: awal210874@yahoo.com
}

\begin{abstract}
Continuous Global Positioning System (GPS) observations showed significant crustal displacements as a result of the Bengkulu earthquake occurring on September 12, 2007. A maximum horizontal displacement of 2.11 $m$ was observed at PRKB station, while the vertical component at BSAT station was uplifted with a maximum of $0.73 \mathrm{~m}$, and the vertical component at LAIS station was subsided by $-0.97 \mathrm{~m}$. The method of adding more constraint on the inversion for the Bengkulu earthquake slip distribution from GPS observations can help solve a least squares inversion with an under-determined condition. Checkerboard tests were performed to help conduct the weighting for constraining the inversion. The inversion calculation of the Bengkulu earthquake slip distribution yielded in an optimum value of slip distribution by giving a weight of smoothing constraint of 0.001 and a weight of slip value constraint $=0$ at the edge of the earthquake rupture area. A maximum coseismic slip of the optimal inversion calculation was $5.12 \mathrm{~m}$ at the lower area of PRKB and BSAT stations. The seismic moment calculated from the optimal slip distribution was $7.14 \times 1021 \mathrm{Nm}$, which is equivalent to a magnitude of 8.5.
\end{abstract}

Keywords: Bengkulu earthquake; GPS data; least squares inversion; slip distribution.

\section{$1 \quad$ Introduction}

Bengkulu is one of the areas in southwest Sumatra, Indonesia, which has been influenced by the subduction activity. Due to its location that is close to the subduction zone of the Indo-Australian oceanic plate beneath the Eurasian plate, this area is prone to earthquakes. It is recorded on the history of seismicity in the western coast of Sumatra that earthquakes with large magnitude occurred in Bengkulu in 1833 (magnitude 8.7), in 2000 (magnitude 7.9) and most recently on 12 September 2007 with the main earthquake magnitude of 8.5 at the depth

Received March 21 ${ }^{\text {st }}, 2012$, Revised July $26^{\text {th }}, 2012$, Accepted for publication July $27^{\text {th }}, 2012$. Copyright (C) 2012 Published by LPPM ITB \& PII, ISSN: 1978-3051, DOI: 10.5614/itbj.eng.sci.2012.44.2.6 
of $34 \mathrm{~km}$. It was followed by other large earthquakes on the same day with a maximum magnitude of 7.9 [1].

GPS is a satellite navigation system as a determinant of the position based on observations of satellites. In recent years GPS techniques have been applied repeatedly in studies on slip rate estimation of active faults in Indonesia. Meilano, et al. [2] used campaign and continuous GPS data to make a preliminary estimation of the slip rate of Lembang fault. The results of these GPS measurements suggest that Lembang fault has shallow creeping and deeper locking portion. Using GPS geodetic surveys, Prawirodirdjo, et al. [3] revealed deformation above the Sumatra subduction zone that shows nearly complete coupling of the forearc to the subducting plate south of $0.5 \mathrm{oS}$ and half as much to the north. Abidin, et al. [4] used GPS surveys method to study the interseismic deformation of three active faults in West Java region (i.e. Cimandiri, Lembang and Baribis faults), and the co-seismic and post-seismic deformation related to the May 2006 Yogyakarta and the July 2006 South Java earthquakes.

Elastic dislocation theory assumes that the crust of the earth is homogeneous, isotropic, linear and elastic [5]. Displacement at an earthquake field will result in a displacement of the earth's surface. The magnitude of the displacement cannot be directly measured, but with the data of the displacements on the earth's surface that can be obtained from GPS measurements, the displacements can be calculated using the inversion method of the data of the displacements on the surface [5]. The problem that arises from this inversion calculation is regarding its nature of resulting solution that is commonly not unique or stable. Thus, several inversion techniques exploiting the linear nature of the problem and involving several kinds of constraints from geophysical and geological information are required to obtain a unique and stable inversion solution [6].

Several studies that calculated the slip distribution associated with of Bengkulu earthquake in 2007 have been conducted by the USGS [7], Gusman, et al. [8] and Ambikapathy, et al. [9]. USGS calculated the slip distribution using teleseismic data and relatively small-sized discrete earthquake rupture area of $20 \mathrm{~km} \times 14.5 \mathrm{~km}$ [7]. Gusman, et al. [8] used the data of tsunami waves and InSAR, while Ambikapathy, et al. [9] used relatively large discrete earthquake based on the Sumatran GPS Array (SuGAr) data. In these studies, none has used least-square inversion calculation using a relatively small discrete earthquake field and data obtained from GPS measurements (near-field). This paper calculates the slip distribution of the earthquake field using the SuGAr measurement data with the least squares inversion technique as well as the constraint of geophysical and geological information thus optimum slip distribution solution is obtained in the case of the Bengkulu earthquake 2007. 


\section{$2 \quad$ Bengkulu Earthquake 2007}

The 2007 Bengkulu earthquake had an epicenter at coordinates $4.520^{\circ} \mathrm{S}$, $101.374^{\circ} \mathrm{E}$ with a depth of $34 \mathrm{~km}$ [1]. The earthquake occurred as a result of the fault slip on the boundary between the Indo-Australian and Eurasian plates. Around the location of the earthquake, the Indo-Australian plate has moved NNE towards the SE Eurasian plate at the speed of approximately $60 \mathrm{~mm} /$ year. The direction of the relative plate motion was oblique to the orientation of the offshore plate boundary along the west coast of Sumatra. The component of the plate movement is perpendicular to the boundaries and accommodated by the faulting force on the offshore plate boundaries. Most of the plate motion components are parallel to the plate boundary and accommodated by strike-slip faulting on the Sumatra fault on the mainland [1].

The seismic moment yielded by the 2007 Bengkulu earthquake according to USGS was $5.05 \times 1021 \mathrm{Nm}$ (equivalent to $\mathrm{Mw}=8.4$ ). Meanwhile, the moment magnitude yielded by USGS from the seismic data was 8.5 and the obtained maximum slip was $4 \mathrm{~m} \mathrm{[7].} \mathrm{Gusman,} \mathrm{et} \mathrm{al.} \mathrm{[8]} \mathrm{performed} \mathrm{a} \mathrm{calculation} \mathrm{of} \mathrm{slip}$ distribution inversion using the data of tsunami waves and InSAR. They divided the earthquake field into 72 discrete with a cell size of $25 \mathrm{~km}$ x $25 \mathrm{~km}$. The result of the inversion calculation carried out by Gusman, et al. [8] produced slip distributions that indicate the maximum value of $\pm 6 \mathrm{~m}$ at two discrete locations. The seismic moment generated by the Bengkulu earthquake, according to Gusman, et al. [8], was $3.8 \times 1021 \mathrm{Nm}$ (equivalent to $\mathrm{Mw}=8.3$ ).

Ambikapathy, et al. [9] also conducted a calculation of the 2007 Bengkulu earthquake slip distribution using the SuGAr data and obtained a maximum slip of $7 \mathrm{~m}$. They only calculated a number of 7 discrete earthquake fields, which is larger compared to those used by USGS and Gusman, et al. [8]. The results of the slip among the discrete were not smooth. Ambikapathy, et al. [9] did not calculate the seismic moment of the resulting slip distribution.

Among the three studies, USGS [7] and Gusman, et al. [8] have already used smaller discrete sizes than that of Ambikapathy, et al. [9]. Yet, it is only USGS [7] that has calculated a larger area of the earthquakes field, reaching up to the edge of the trench. Assuming that the earthquake field is the field that experienced continuous ruptures, but whose slip values were not homogeneous, by the use of a smaller discrete size, it is expected that the resulting slip distribution would be more appropriate to the actual physical phenomena.

The data used by USGS are categorized as far-field data (observed from a distance), thereby making them relatively less sensitive than those of GPS observation data (SuGAr) as performed by Ambikapathy, et al. [9] or the 
tsunami wave data and InSAR in capturing the phenomenon of the earthquake field slips.

Therefore, in this study least squares inversion slip distribution is performed by treating the earthquake fields as small size discrete areas and using the nearfield SuGAr data. Global CMT solution also calculated the seismic moment and moment magnitude of the Bengkulu earthquake [10]. The result of the seismic moment calculation was $6.71 \times 1021 \mathrm{Nm}$, which is equivalent to $\mathrm{Mw}=8.5$.

\section{$3 \quad$ Least Squares Inversion}

With the linear relationship between data $(d)$ and the model parameter $(m)$, the calculation of the inversion can be performed using the following procedure:

$$
d=G . m
$$

with $G$ as a common modeling function that relates the model into quantity in the data domain. In other words, the function $G$ allows us to predict the data for a particular model $m$ [11].

One of the commonly used inversion techniques is the least squares calculation method. The completion of the least squares inversion is to estimate parameter $\mathrm{m}$, which has a response (calculated data) that matches the field data. Therefore, the criterion of the number of minimum error square (least-square) is re-applied to obtain the solution or model $m$ [12].

The parameter for model $m$ can be calculated by the least squares inversion, with the following equation [11]:

$$
m=\left(G^{T} G\right)^{-1} G^{T} d
$$

If the calculation of the inversion uses some weights, the Eq. (2) becomes:

$$
m=\left(G^{T} W_{e} G\right)^{-1} G^{T} W_{e} d
$$

$W_{e}$ serves as the weight matrix and $\mathrm{T}$ is the transpose matrix.

Elastic dislocation formula can be used to calculate the displacement of the points on the surface when the values of the dip-slip and strike-slip are known $[5,13]$. According to Elastic dislocation formula, the values of the displacement on the surface are directly proportional to the values of the strike-slip, dip-slip and opening in a linear manner. By utilizing the properties of the linearity of the equation that connects the displacement in the field of the earthquake to the displacement of the points on the surface, matrix $G$ can be constructed. In equation (1), vector $m$ is the model parameter to be searched. In this case $m$ is 
the strike-slip and dip-slip from the earthquake field, and matrix $d$ consists of vectors of the displacement of the points on the surface.

By making the value of the slip equal to one scaling unit, the displacement of the point on the surface can be calculated. If the slip value equals to $\mathrm{n}$ times of the scaling unit, with a linear relationship, the value of the surface point displacement equals to $n \times G_{0}$. Such an assumption leads to the making of matrix $G$ by calculating the point displacement on the surface, inserting the slip value as equal to one unit of the scale. Subsequently, matrix $G$ is called the basis matrix.

The slips in the earthquake rupture area have a spatial variation of model parameters that are not too high in term of the inversion calculation. The difference of the adjacent model parameter values is minimized through smoothing. One of the matrix smoothing models $(M S)$ that is used to smooth the least squares inversion solution can be viewed at the following $M S$ matrix [11].

$$
M S=\left(\begin{array}{ccccccc}
1 & -2 & 1 & 0 & \cdots & \cdots & 0 \\
0 & 1 & -2 & 1 & 0 & \cdots & \vdots \\
\vdots & \cdots & \cdots & \cdots & \cdots & \cdots & \vdots \\
\vdots & \cdots & 0 & 1 & -2 & 1 & 0 \\
0 & \cdots & \cdots & 0 & 1 & -2 & 1
\end{array}\right)
$$

Another constraint used in this study is to give the slip on the edge of the earthquake slip area a discreet value $=0$. If the constraint is added into the inversion calculation, the Eq. (1) will be:

$$
\left(\begin{array}{c}
G_{H o r} \\
G_{V e r} \\
P 3 . S \\
P 4 . T
\end{array}\right) \cdot m=\left(\begin{array}{c}
P 1 \cdot d_{H o r} \\
P 2 . d_{V e r} \\
0 \\
0
\end{array}\right)
$$

$\mathrm{P} 1=$ weight for horizontal measurement data

P2 = weight for vertical measurement data

P3 = weight for smoothing constraint

P4 = weight for constraint of slip value = zero at the edge of the earthquake field discrete

$G_{H o r}=$ Basis matrix for horizontal measurement data

$G_{V e r}=$ Basis matrix for vertical measurement data

$d_{\text {Hor }}=$ Horizontal measurement data

$d_{\text {Ver }}=$ Vertical measurement data

$\mathrm{S} \quad=$ Basis matrix for smoothing constraint

$\mathrm{T}=$ Basis matrix for constraint of slip value $=$ zero at the edge of the earthquake field discrete 


\section{$4 \quad$ Earthquake Source Model}

The model parameters of the earthquake source used in the calculation are:

1. Earthquake rupture area geometry consisting of long $(\mathrm{L})=68900 \mathrm{~m}$, width $(\mathrm{W})=183324 \mathrm{~m}$, the coordinates of the upper midpoint of the earthquake field $(\lambda, \varphi)=\left(100.228^{0},-3.904^{0}\right)$, strike $(\alpha)=141.719^{0}, \operatorname{dip}(\delta)=-13.097^{0}$ and depth $(\mathrm{D}=5000 \mathrm{~m})$;

2. Strike-slip (ss) and dip-slip (ds) as the parameters that will be estimated and the opening $=0$;

One common approach to the problem of the earthquake slip distribution inversion is to divide the earthquake fields into several uniform discrete units so that the number of slips known is less than the number of the data. The unknown slips are then estimated using the least squares method. The weakness of using this kind parameter is that specific discrete geometry may not provide adequate spatial representation of the various fault slips due to faults being discretized very roughly or the discrete size that is still too large. In order to estimate continuous distribution of slips, the earthquake field discrete element must be relatively small. In general, this means that the number of model parameters will increase and may exceed the number of the data. Therefore, the equation system becomes ill posed (i.e., the systems are underdetermined and the solution is not unique) [6]. Thus, to find a particular solution, constraint can be added to the system of equations.

In this study the earthquake rupture is made by a number of $30 \times 10$ discrete units, and therefore there are 300 slip planes. Each plane of the earthquake has two parameters (strike-slip and dip-slip), bringing the total number of 600 parameters.

\section{Coseismic Displacement from GPS Observations}

The SuGAr data used in this study are the data of 2006, 2007 and 2008, and the number of the GPS stations is 13. Dual-frequency carrier phase and pseudorange observation were processed using Bernese GPS processing software version 5.0 by Hugentobler, et al. [14], developed at the University of Bern. The International GNSS service (IGS) precise ephemeris earth rotation parameters were used and the coordinate reference system was established by connecting to the nearby IGS stations. Integer biases were fixed with QuasiIonosphere Free (QIF). All relevant geodynamic reductions were applied in order to enable a careful determination of crustal deformation. The ocean tidal loading was considered using the GOT00 model by Bos and Scherneck [15]. The results of the SuGAr data processing are the daily coordinates of each SuGAr station. The topocentric coordinates on the first day of each station 
serves as the origin of the topocentric coordinate system of each respective station, hence each station has its own topocentric coordinate system.

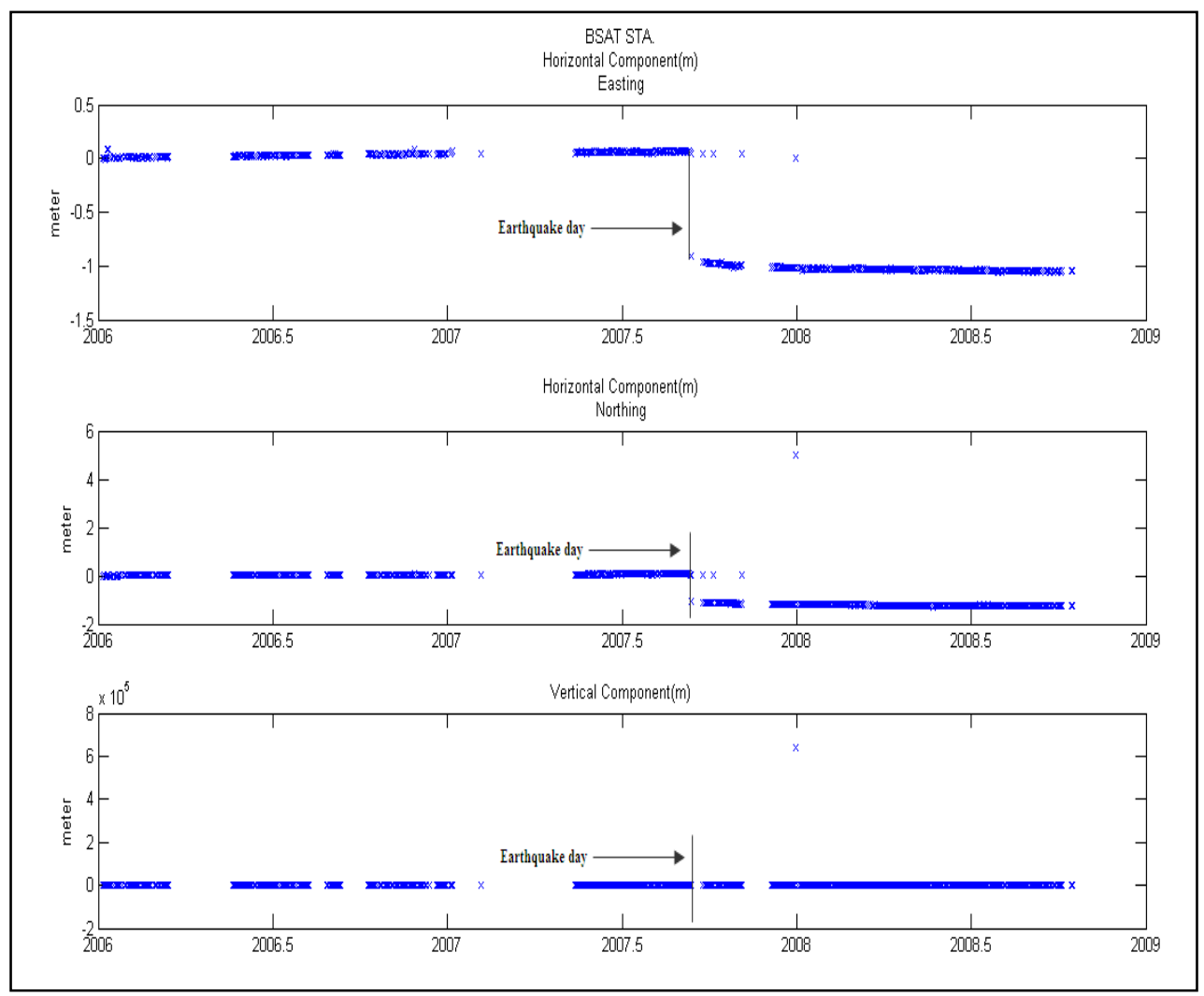

Figure 1 Daily coordinates of BSAT station from 2006 - 2009.

From the time series (Figures 1 and 2), topocentric coordinates of each SuGAr stations (Table 1), ten data were taken before the earthquake (including data on the day of the earthquake) and ten data after the earthquake. Then the average values and deviation standard of each ten data were calculated. If the deviation between the data and the average value exceeds one deviation standard, the coordinate data are rejected. The accepted data are then calculated for their average values. The difference of the average values of the accepted data before and after the earthquake is the displacement vector due to the earthquake coseismic as shown at Table 1 and Figure 3. 


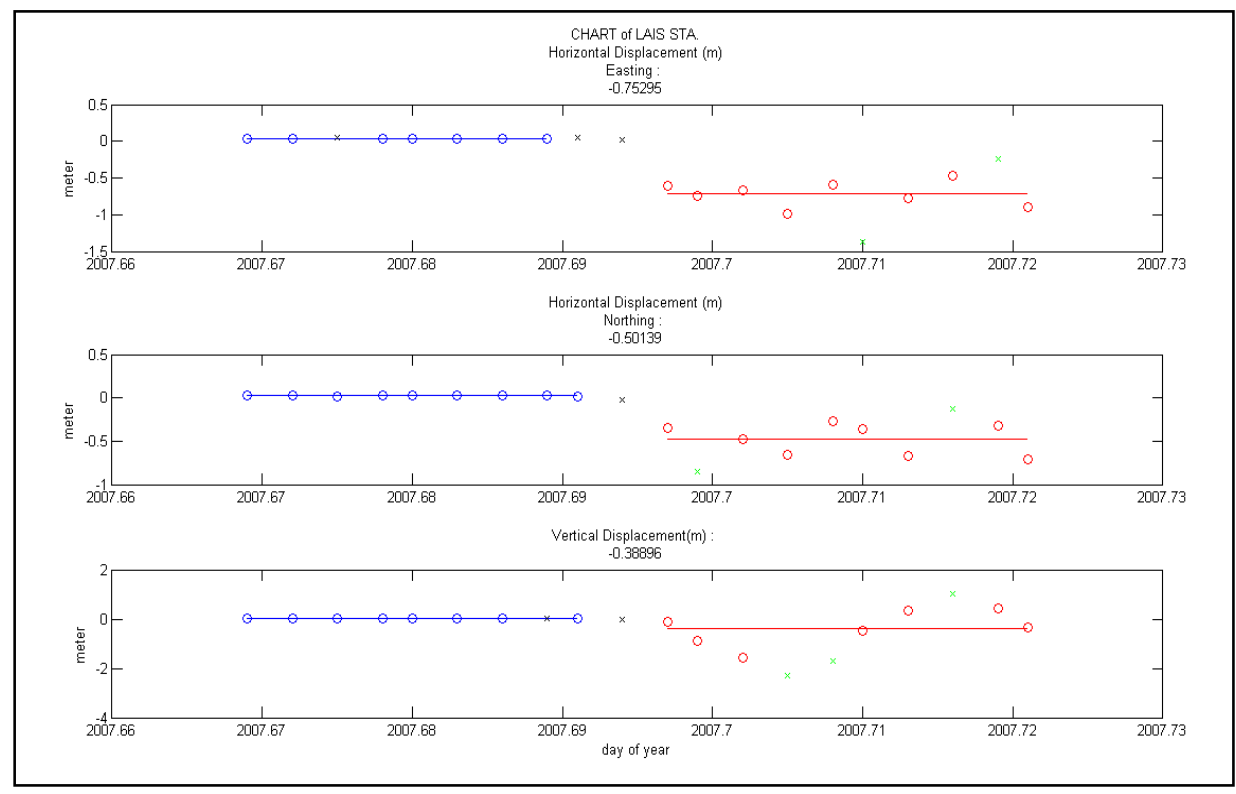

Figure 2 Calculation result of co-seismic vector of LAIS station.

Table 1 Displacement vector of SuGAr stations due to co-seismic of the Bengkulu earthquake.

\begin{tabular}{ccccccc}
\hline \multirow{2}{*}{ STA } & \multicolumn{3}{c}{ Displacement (m) } & \multicolumn{3}{c}{ Deviation Standard (m) } \\
\cline { 2 - 7 } EW & NS & UD & EW & NS & UD \\
\hline BSAT & -1.029 & -1.174 & 0.728 & 0.014 & 0.015 & 0.006 \\
BTET & -0.015 & 0.013 & -0.004 & 0.004 & 0.004 & 0.003 \\
JMBI & -0.080 & -0.054 & -0.001 & 0.005 & 0.007 & 0.006 \\
LAIS & -0.753 & -0.501 & -0.389 & 0.088 & 0.090 & 0.357 \\
LNNG & -0.477 & -0.575 & -0.165 & 0.082 & 0.110 & 0.241 \\
MKMK & -0.578 & -0.709 & -0.204 & 0.016 & 0.018 & 0.010 \\
MLKN & 0.026 & -0.009 & -0.033 & 0.005 & 0.003 & 0.008 \\
MNNA & -0.072 & -0.002 & -0.016 & 0.005 & 0.003 & 0.007 \\
MSAI & -0.008 & 0.034 & -0.002 & 0.005 & 0.007 & 0.004 \\
NGNG & -0.103 & -0.035 & 0.023 & 0.048 & 0.001 & 0.017 \\
PPNJ & -0.486 & -0.571 & 0.257 & 0.010 & 0.007 & 0.011 \\
PRKB & -1.252 & -1.701 & -0.318 & 0.102 & 0.103 & 0.279 \\
PSKI & -0.126 & -0.227 & -0.040 & 0.003 & 0.001 & 0.005 \\
\hline
\end{tabular}



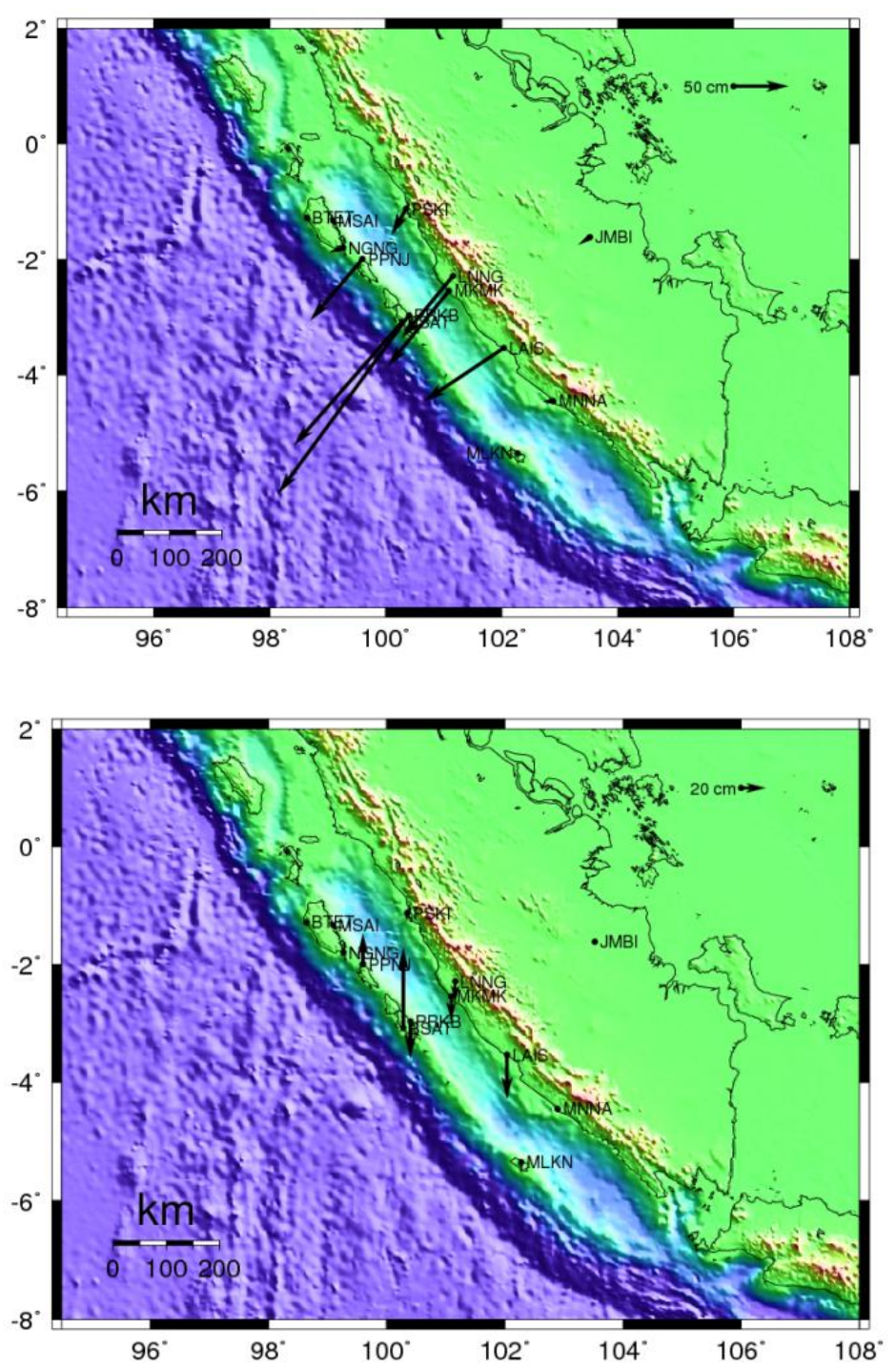

Figure 1 Displacement vectors of GPS SuGAr stations (the upper panel: horizontal displacement, and the lower panel: vertical displacement).

\section{$6 \quad$ Least Squares Inversion Calculation}

Serving as the input data in the calculation is a discrete model of earthquake plane, coordinates of observation points and displacement vectors of SuGAr points. The parameters to be estimated are strike-slip and dip-slip of each discrete earthquake plane. If a calculation of slip distribution is to be performed 
at $(\mathrm{m} \times \mathrm{n})$ discrete earthquake field, the number of parameters to be estimated is $2 \times(m \times n)$.

Basis matrix $(G)$ was constructed by performing a forward calculation of displacement of SuGAr ( $k$ number of observation point) for each model of the discrete field by setting a value of dip-slip $=1$ and strike-slip $=0$ for the dip-slip basis matrix component. The result of the forward calculation was $(3 \times k)$ displacement data. Thus, for the discrete field the size of $m \times n$ with a number of SuGAr $k$ points used, a basis matrix for dip-slip would be obtained with the size of $(3 \times k)$ rows and $(m \times n)$ columns. The strike-slip basis matrix was made in the same manner but using the dip-slip $=0$ and strike-slip $=1$. The dip-slip basis matrix and the strike-slip matrix were subsequently combined to form a matrix $\mathrm{G}$ with the size of $(3 \mathrm{x} k)$ rows and $2 \times(m \times n)$ columns. The constraints used in this study were smoothing constraint and constraint of the slip with zero value at the edge of the discrete earthquake field.

The smoothing constraint matrix on the discrete $(m \times n)$ was for the dip-slip and strike-slip. Size of matrix was $(2 \times(((m-2) \times n)+((n-2) \times m)))$ rows and $(2 \times$ $(m \times n))$ columns. The matrix for constraint slip = zero at the discrete of the edge of the earthquake field was for the values of dip-slip and strike-slip of the size $((2 \times m)+(2 \times(n-2)))$ rows and $(2 \times(m \times n))$ columns.

The $d$ column matrix was constructed from the displacement data of SuGAr point with the size of $(3 \times k)$. In the process of calculation, matrix $G$ was combined with the constraint matrix. The $d$ column matrix was also added with a value of 0 as many as the number of the rows of the constraint matrix used.

The weight matrix was structured as a diagonal matrix with the size of a number of rows of matrix $G$ plus the rows of the constraint matrix used. The diagonal elements are the weight values of the horizontal and vertical displacement data and the constraint weight used.

From the results of the calculation, the values of the parameter of dip-slip and strike-slip of each discrete earthquake field can be obtained. These parameters can be incorporated into the models of the earthquake field to perform a forward calculation of the displacement of the points on the surface.

\subsection{Checkerboard Test}

Checkerboard test (CBT) was conducted to perform the appropriate weighting for observation equation of base and constraint matrices. CBT was performed using synthetic data as the results of the forward calculation using synthetic earthquake field model. 
Checkerboard tests were carried out using various weighting i.e. weights for horizontal observation data $(P 1)$, weights for vertical observation data $(P 2)$, weights for smoothing constraint $(P 3)$ and weights for the constraint of the slip with zero value at the edge of the discrete earthquake field (P4).

The synthetic models were made by determining a dip-slip value $=-5 \mathrm{~m}$ and a strike-slip $=0 \mathrm{~m}$ in the 3 parts and the values of dip-slip $=0 \mathrm{~m}$ and a strike-slip $=0 \mathrm{~m}$ in the other 3 parts as shown at figure 4 . The black-colored vectors indicate displacements on the surface as the results of the forward calculation of the synthetic model. The orange-colored vectors are the synthetic dip-slip models.

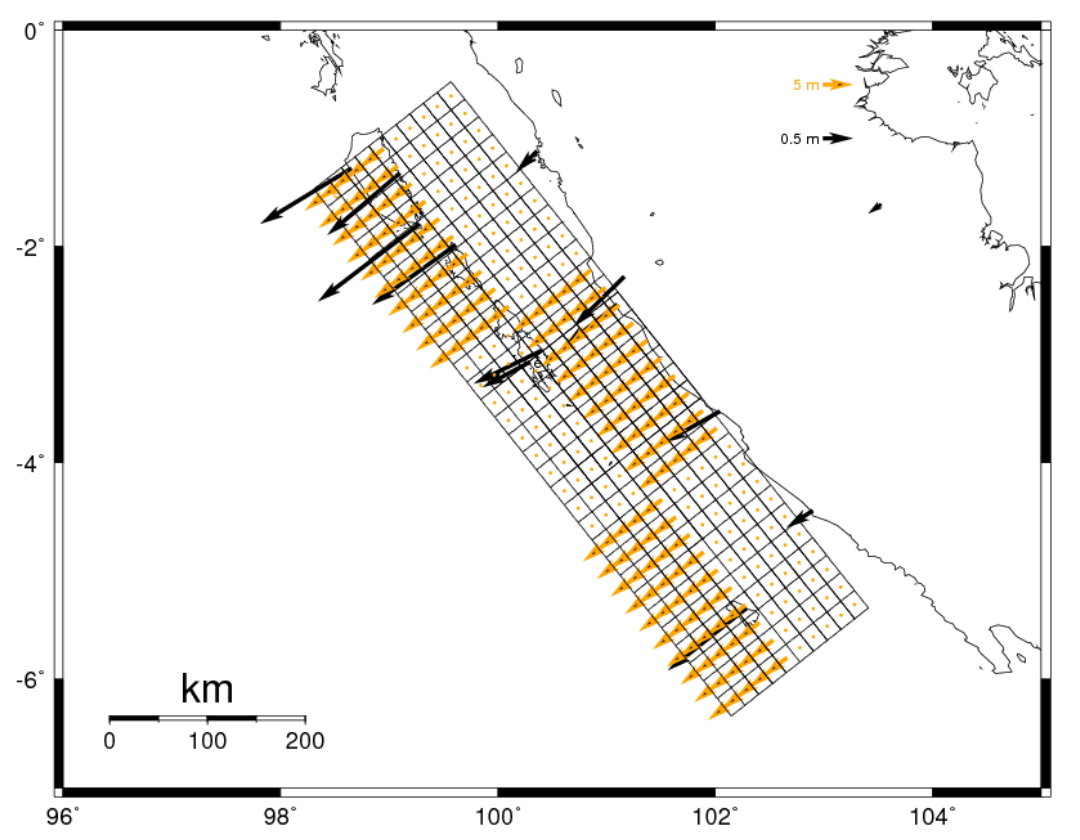

Figure 2 Discrete synthetic model 30 x 10.

The weighting variations had been conducted for $P 3$ and $P 4$, while for $P 1$ the weight was determined $=1$ and $P 2=0.1$. The weight variations to be performed are as follows. There are 12 weights for $P 3$ and $P 4$. Each weight value of $P 3$ would be paired alternately with 12 weights of $P 4$; thus, 144 possible variations of weights $P 3$ and $P 4$ would be obtained. The test results of RMS1 and RMS2 yielded a minimum RMS value on the weight pair of $P 3=0.005$ and $P 4=$ 0.0001 .

In the next step, an inversion calculation was performed with three variations of weights chosen as follows: 
1. $P 1=1, P 2=0.3, P 3=0.005$ and $P 4=0.0001$

2. $P 1=1, P 2=0.3, P 3=0.005$ and $P 4=0.0005$

3. $P 1=1, P 2=0.3, P 3=0.001$ and $P 4=0.0001$

\subsection{Inversion using the SuGAr Data Weight Combination 1}

In this model the maximum value of the slip is $3.74 \mathrm{~m}$ (figures 5 and 6). The slip direction inclines toward the trench which indicates that the dip-slip value is more dominant than the strike-slip, except in the discrete southeast and northwest edges. The maximum value of the slip is located around the lower parts of PRKB and BSAT stations, and tends to decline toward the edge of the earthquake fields.

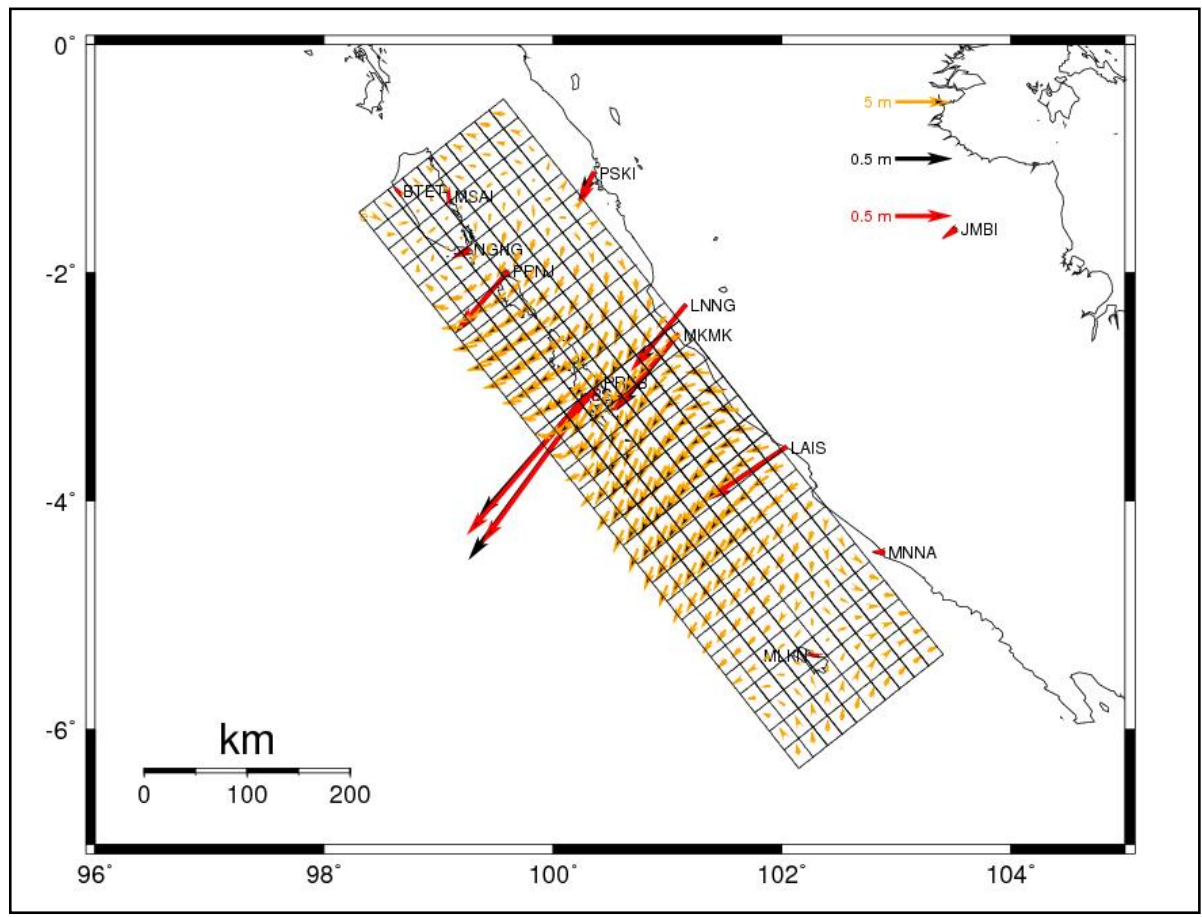

Figure 3 Slip distribution as the results of the inversion with the discrete SuGAr data of $30 \times 10$ with weight combination 1 (black vectors are the vectors of the point displacement using SuGAr data; red vectors are the vectors of the model displacement; and orange vectors are the slip yielded from the inversion of the discrete field). 


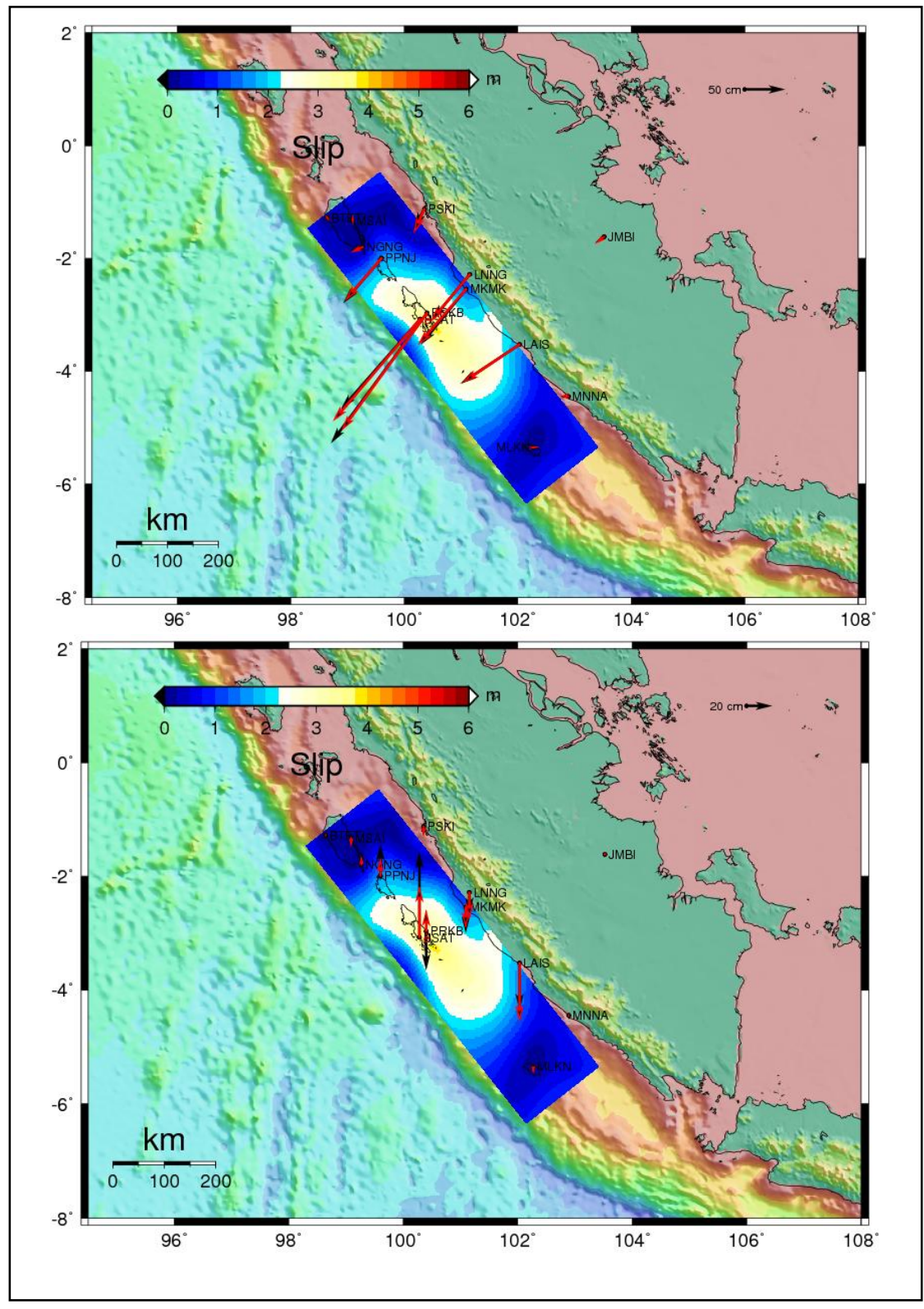

Figure 4 The contour of the slip distribution resulting from the inversion using SuGAr data of discrete $30 \times 10$ with weight combination 1 (the upper image is the horizontal component, the lower image is the vertical component, the black vectors are the vectors of point displacement using SuGAr data, the red vectors are the vectors of the model displacements). 


\subsection{Inversion Using the SuGAr Data Weight Combination 2}

Here, the slip maximum value is $3.95 \mathrm{~m}$ (Figures 7 and 8). The slip direction also inclines toward the trench showing that the dip-slip is more dominant than the strike-slip, except in the discrete southeast and northwest edges. The maximum slip value is located around the lower parts of stations PRKB and BSAT and tends to decline toward the edge of the earthquake fields.

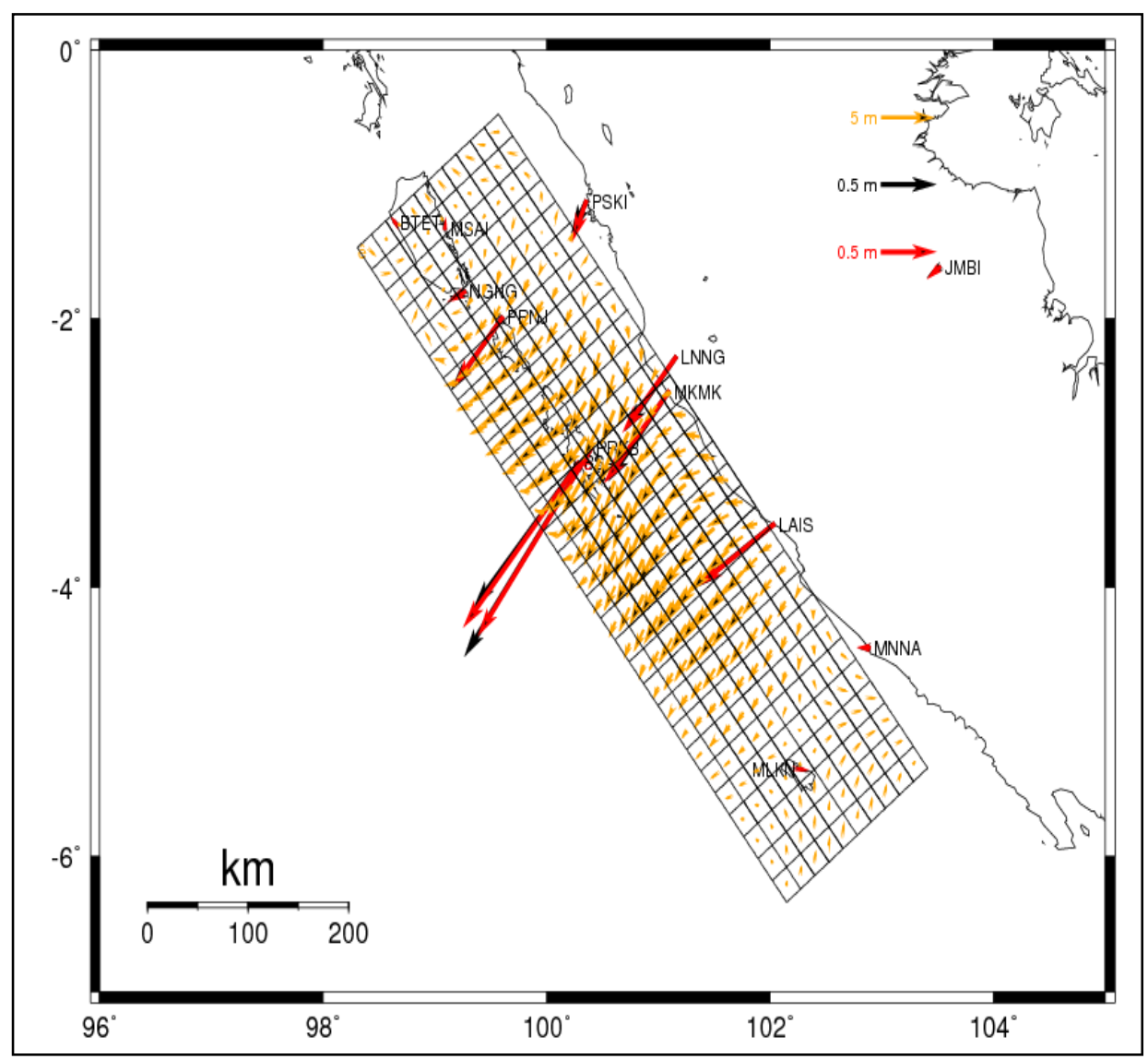

Figure 5 Slip distribution as the results of the inversion with the discrete SuGAr data of $30 \times 10$ with weight combination 2 (black vectors depict the vectors of the point displacement using SuGAr data, red vectors are the vectors of the model displacement; and orange vectors are the slip yielded from the inversion of the discrete field). 


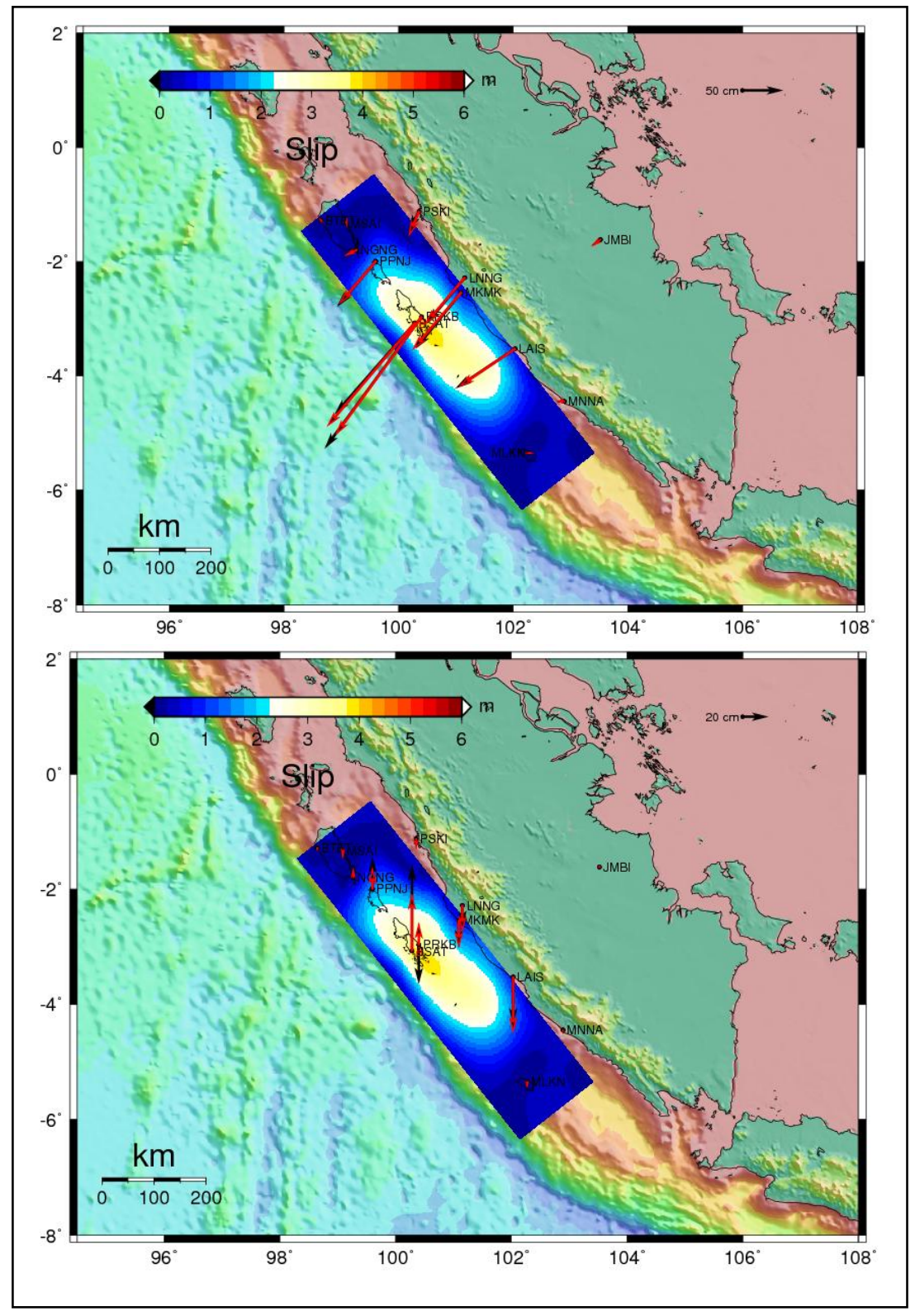

Figure 6 The contour of the slip distribution resulting from the inversion using SuGAr data of discrete $30 \times 10$ with weight combination 2 (the upper image is the horizontal component, the lower image is the vertical component, the black vectors are the vectors of point displacement using SuGAr data, and the red vectors are the vectors of the model displacements). 


\subsection{Inversion Using the SuGAr Data Weight Combination 3}

By using combination 3 the slip maximum value is $5.12 \mathrm{~m}$ (figures 9 and 10). The slip direction also inclines toward the trench that shows that the dip-slip is more dominant than the strike-slip, except in the discrete southeast and northwest edges. The maximum slip value is around the lower parts of stations PRKB and BSAT, which tends to decline toward the edge of the earthquake fields.

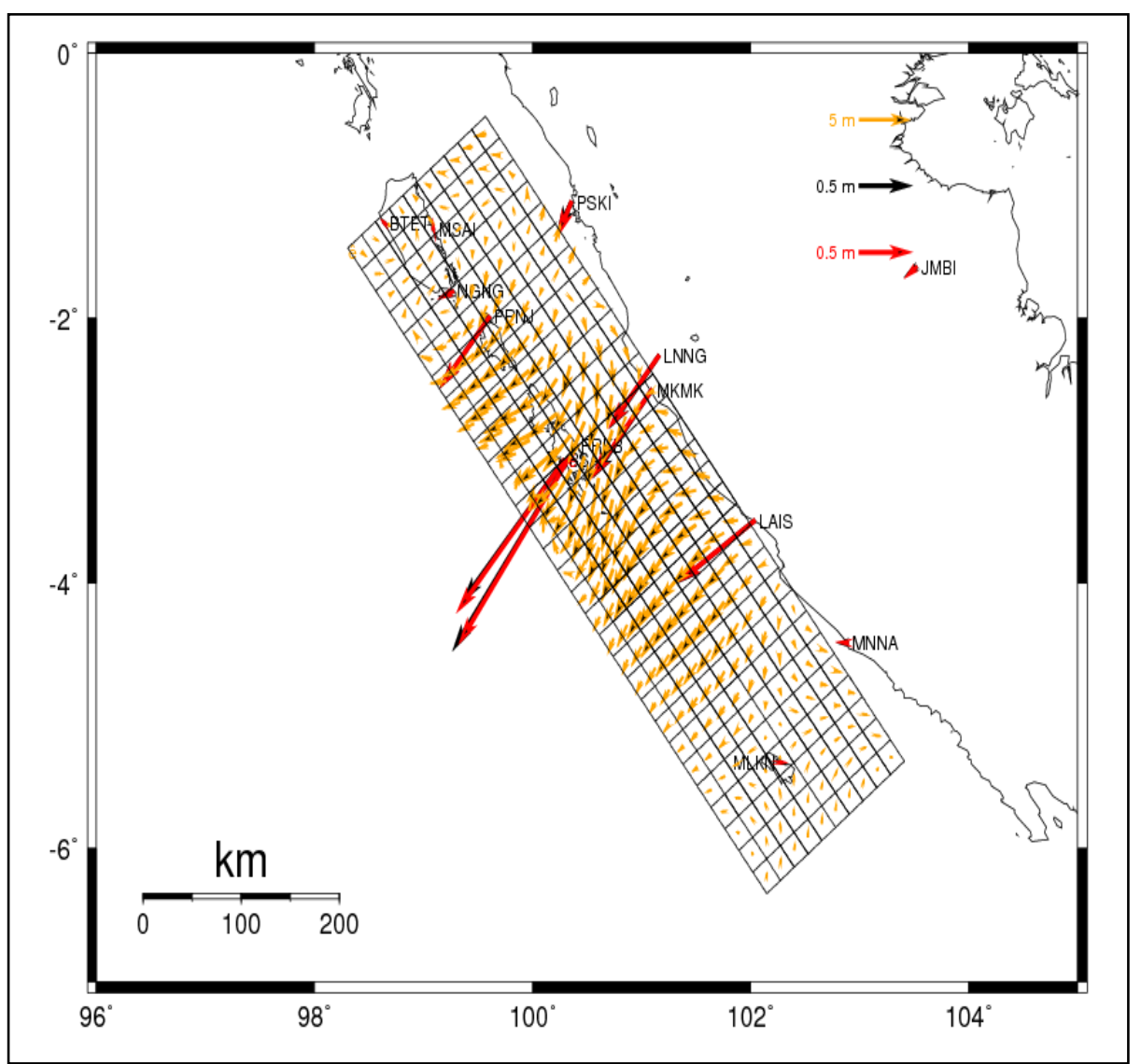

Figure 7 Slip distribution as the results of the inversion with the discrete SuGAr data of $30 \times 10$ with weight combination 3 (black, red and orange vectors are the vectors of the point displacement using the SuGAr data, the vectors of the model displacement and the slips yielded from the inversion of the discrete field, respectively). 


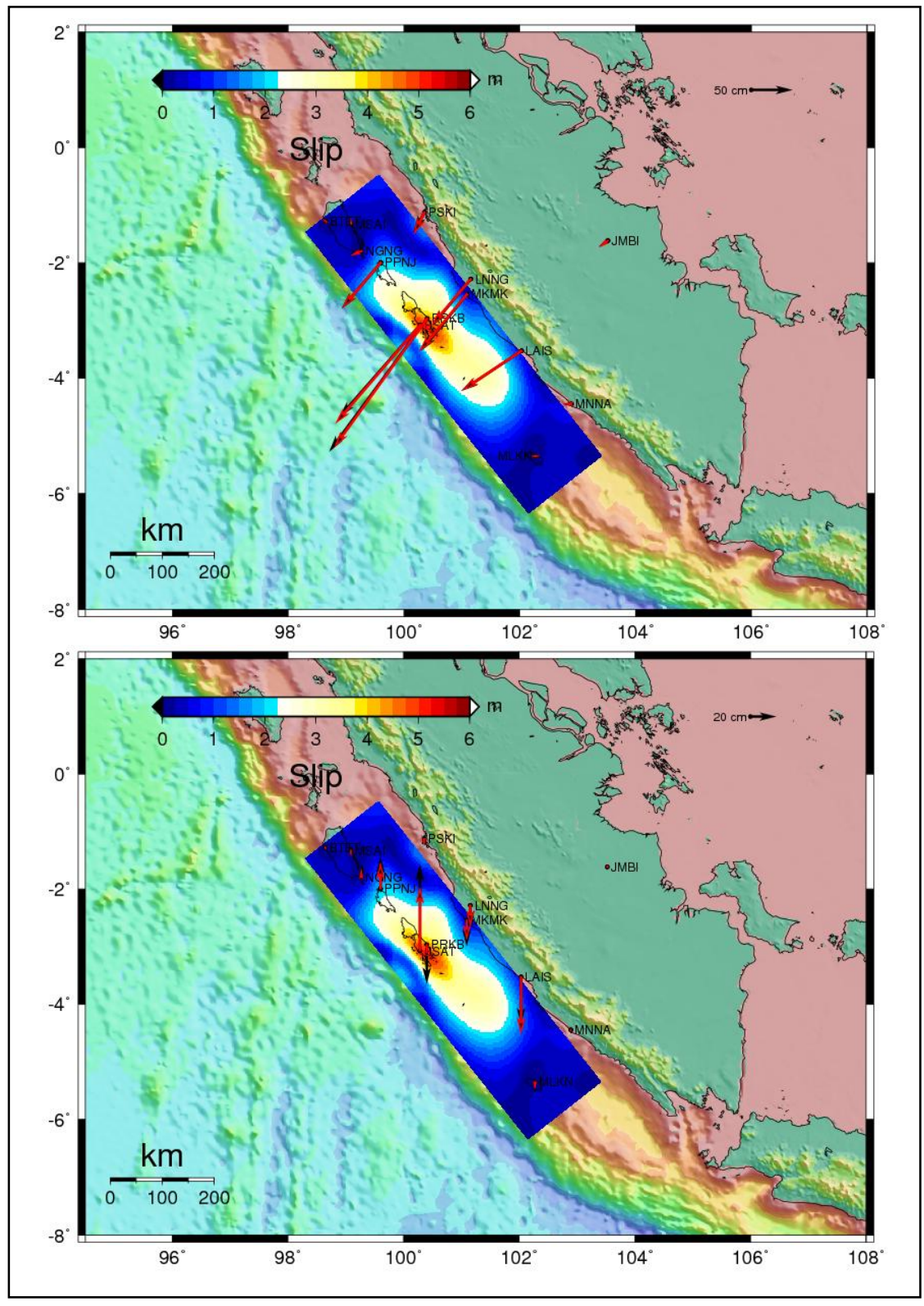

Figure 8 The contour of the slip distribution resulting from the inversion using the SuGAr data of discrete $30 \times 10$ with weight combination 3 (the upper image is the horizontal component, the lower image is the vertical component, the black and red vectors depict the vectors of point displacement using the SuGAr data, the vectors of the model displacements, respectively). 


\section{$7 \quad$ Seismic Moment and RMS Estimation}

The seismic moment was calculated using the assumed value of $\mu$ coefficient (coefficient of rigidity) $=4 \times 10^{10} \mathrm{~N} \cdot \mathrm{m}^{-2}$ (table 2). Moment magnitude was calculated using the formula of Kanamori and Anderson [16].

Table 2 Seismic moment and moment magnitude (Mw).

\begin{tabular}{lcr}
\hline & Moment (N.m) & Mw \\
\hline discrete 30x10 weight 1 & $7.452 \mathrm{E}+21$ & 8.5 \\
discrete 30x10 weight 2 & $6.501 \mathrm{E}+21$ & 8.5 \\
discrete 30x10 weight 3 & $7.140 \mathrm{E}+21$ & 8.5 \\
USGS [7] & $5.050 \mathrm{E}+21$ & $8.4\left(8.5^{*}\right)$ \\
Gusman, et al. [8] & $3.800 \mathrm{E}+21$ & 8.3 \\
Global CMT Solution & & $\left.8.5^{* *}\right)$ \\
[10] & $\left.6.71 \mathrm{E}+21^{* *}\right)$ & \\
\hline$*$ ) results from seismic data & & \\
\hline$*$ results from seismic data & & \\
\hline
\end{tabular}

The slip distributions resulting from the inversion were used to calculate the displacements in the SuGAr stations, hence vectors of model displacement were obtained. The RMS values of the observed and calculated displacement vectors are shown in Table 3.

Table 3 RMS of the displacement vectors of SuGAr stations with model vector.

\begin{tabular}{cccc}
\hline \multirow{2}{*}{ Types of discrete } & \multicolumn{3}{c}{ RMS (meter) } \\
\cline { 2 - 4 } & RMS & RMS horizontal & RMS vertikal \\
\hline discrete 30 x 10 weight 1 & 0.109 & 0.061 & 0.173 \\
discrete 30 x 10 weight 2 & 0.106 & 0.063 & 0.165 \\
discrete 30 x 10 weight 3 & 0.061 & 0.028 & 0.100 \\
\hline
\end{tabular}

RMS values for horizontal component ranged from $28 \mathrm{~mm}$ to $63 \mathrm{~mm}$, while the vertical component was $100 \mathrm{~mm}$ to $173 \mathrm{~mm}$. The smallest RMS value in the inversion was the one resulting from the use of weight combination 3 .

\section{$8 \quad$ Closing Remarks}

The patterns of the slip resulting from the inversion with every weight combination used are almost similar, i.e. the maximum slips are concentrated around stations PRKB (Pagai Island) and BSAT (Pagai Island) and then they decrease toward the edge of the earthquake fields. In addition, the values of dip- 
slip direction tend to be more dominant and the slip direction tends toward the trench. This is consistent with the mechanism of the Bengkulu earthquake with its dominant dip-slip.

The three weight combinations used to calculate the inversion give the values of seismic moment, which are similar to the seismic moment of the earthquake calculated from the USGS teleseismic data. On the other hand, the values of RMS of the residual vector of the GPS data and models, the weight combination 3 yields the smallest RMS value. Therefore, the weight combination 3 at the discrete $30 \times 10$ is considered to give the optimal slip distribution value.

The maximum slips in this paper are $3.75 \mathrm{~m}, 3.95 \mathrm{~m}$ and $5.12 \mathrm{~m}$, while the maximum value of slip resulting from the USGS study, Gusman, et al. [8] and Ambikapathy, et al. [9] are $4 \mathrm{~m}, \sim 6 \mathrm{~m}$ and $7 \mathrm{~m}$, respectively. The location of maximum slip of these studies is consistent, i.e. around the Pagai Island. Thedirection of slip vectors resulting from this paper, USGS and Ambikapathy, et al. [9] is similar, i.e. toward the trench.

\section{References}

[1] USGS, http://neic.usgs.gov/neis/eq_depot/2007/eq_070912_hear/neic_ hear_l.html (12 May 2010).

[2] Meilano, I., Abidin, H. Z., Andreas, H., Gumilar, I., Sarsito, D., Rahma Hanifa, Rino, Harjono, H., Kato, T., Kimata, F. \& Fukuda Y., Slip Rate Estimation of the Lembang Fault West Java from Geodetic Observation, Journal of Disaster Research, 7(1), 2012.

[3] Prawirodirdjo, L., Bock, Y., McCaffrey, R., Genrich, J., Calais, E., Stevens, C., Puntodewo, S.S.O., Subarya, C., Rais, J., Zwick, P. \& Fauzi., Geodetic Observations of Interseismic Strain Segmentation at the Sumatra Subduction Zone, Geophys. Res. Lett., 24(21), pp. 2601-2604, November 1, 1997.

[4] Abidin, H.Z., Andreas, H., Kato, T., Ito, T., Meilano, I., Kimata, F., Natawidjaja D.H., Harjono, H., Crustal Deformation Studies in Java (Indonesia) Using GPS, Journal of Earthquake and Tsunami, 3(2), (2009) 77-88.

[5] Okada, Y., Surface Deformation Due to Shear and Tensile Faults in A Half Space, Bull. Seism. Soc. Am., 75, pp. 1135-1154, 1985.

[6] Du, Y., Aydin A. \& Segall, P., Comparison of Various Inversion Techniques as Aplied to the Determination of a Geophysical Deformation Model for the 1983 Borah Peak Earthquake, Bull. Seism. Soc. Am., 82(4), pp. 1840-1866, 1992.

[7] USGS, http://earthquake.usgs.gov/earthquakes/eqinthenews/2007/us2007 hear/finite_fault.php (12 May 2010). 
[8] Gusman, A., Latief, H., Pandoe, W. \& Tanaka, Y., Source Model of the 2007 Bengkulu Earthquake Determined from Tsunami Waveforms and InSAR Data, Symposium on "Estimating the Recurrence Interval and Behavior of Tsunamis in the Indian Ocean via a Survey of Tsunamirelated Sedimentation", Tsukuba, 2009.

[9] Ambikapathy, A., Catherine, J.K., Gahalaut, V.K., Narsaiah, M., Bansal, A. \& Mahesh, P., The 2007 Bengkulu Earthquake, Its Rupture Model and Implications for Seismic Hazard, J. Earth Syst. Sci., 119(4), pp. 553-560, Indian Academy of Sciences, 2010.

[10] Global CMT, http://www.globalcmt.org/ (3 August 2010).

[11] Menke, W., Geophysical Data Analysis: Discrete Inverse Theory, Academic Press. San Diego, California, 1989.

[12] Lawson, C.L. \& Hanson, D.J., Solving Least Squares Problems, PrenticeHall, Englewood Cliffs, New Jersey, 1974.

[13] Segall, P., Earthquake and Volcano Deformation, Princeton University Press. New Jersey, 2010.

[14] Hugentobler, U., Dach, R. \& Fridez, P. (Eds.), Bernese GPS Software, Version 5.0, University of Bern, 2004.

[15] Bos, M.S. \& Scherneck, H.G., Free Ocean Tide Loading Provider, 2004, http://www.oso.chalmers.se/loading/ (5 August 2010).

[16] Kanamori H. \& Anderson, D.L., Theoretical Basis of Some Empirical Relations In Seismology, Bull. Seismol, Soc. Am., 65:1073-95, 1975. 